\title{
Analisa Pengaruh Penambahan Hidrogen Peroksida Terhadap Kualitas Pulp Di EOP Stage
}

Rachmawati Apriani ${ }^{1,1 *}$, Riedo Nugraha ${ }^{1}$

${ }^{1}$ Teknologi Pengolahan Pulp dan Kertas, Fakultas Vokasi, Insitut Teknologi Sains Bandung, Indonesia

ABSTRAK Penelitian dengan judul "Optimasi Pengaruh Penambahan Hidrogen Peroksida Terhadap Kualitas Pulp di EOP Stage" bertujuan untuk mengetahui dosis optimal yang memenuhi standar kualitas EOP Stage. Proses pemutihan di EOP (Ektraksi Oksidasi Peroksida) Stage merupakan proses pemutihan pulp dengan menggunakan bahan kimia yaitu $\mathrm{H}_{2} \mathrm{O}_{2}$. Parameter yang digunakan yaitu kappa number, viscosity, dan brightness. Pulp di bleaching menggunakan 5 variasi dosis yaitu $0,3 \mathrm{ml} \mathrm{H}_{2} \mathrm{O}_{2}, 0,4 \mathrm{ml} \mathrm{H}_{2} \mathrm{O}_{2}, 0,6 \mathrm{ml} \mathrm{H}_{2} \mathrm{O}_{2}, 0,7 \mathrm{ml} \mathrm{H}_{2} \mathrm{O}_{2}$ dan $0,9 \mathrm{ml} \mathrm{H} \mathrm{O}_{2}$. Dari semua variasi dilakukan disimpulkan bahwa dosis yang optimal untuk menghasilkan kualitas pulp yang baik adalah $0,6 \mathrm{ml}$ dan $0,7 \mathrm{ml}$ dengan hasil nilai kappa number untuk $0,6 \mathrm{ml}_{2} \mathrm{O}_{2}$ adalah 1,3 dan 1,4 dan dosis $0,7 \mathrm{ml} \mathrm{H}_{2} \mathrm{O}_{2}$ adalah 1,14 dan 1,2. Lalu viscosity dari $0,6 \mathrm{ml} \mathrm{H}_{2} \mathrm{O}_{2}$ adalah $708 \mathrm{~cm}^{3} / \mathrm{g}$ dan $713 \mathrm{~cm}^{3} / \mathrm{g}$ sedangkan pada dosis $0,7 \mathrm{ml} \mathrm{H} \mathrm{O}_{2}$ adalah $703 \mathrm{~cm}^{3} / \mathrm{g}$ dan $707 \mathrm{~cm}^{3} / \mathrm{g}$. Kemudian brightness dari $0,6 \mathrm{ml} \mathrm{H}_{2} \mathrm{O}_{2}$ adalah $79,62 \%$ dan $79,45 \%$ sedangkan pada dosis $0,7 \mathrm{ml} \mathrm{H}_{2} \mathrm{O}_{2}$ adalah $80,73 \%$ dan $80,12 \%$.

Kata kunci : $\mathrm{H}_{2} \mathrm{O}_{2}$, bleaching, kualitas pulp, EOP Stage

1* Corresponding author: rachmawatiapriani46@gmail.com 


\section{PENDAHULUAN}

Pada era industri 4.0 perkembangan ilmu pengetahuan semakin merambah luas. Hal ini juga berdampak di ilmu teknologi pengolahan pulp dan kertas di indonesia yang semakin berkembang. Dengan perkembangan industri pulp dan kertas yang semakin pesat, maka kebutuhan kertas terus meningkat dari tahun ke tahun. Kenaikannya diperkirakan dapat mencapai 3,5\% tiap tahun, tetapi belum dapat memenuhi semua kebutuhan dalam negeri dan permintaan ekspor untuk kertas. Berdasarkan APKI (Asosiasi Pulp dan Kertas Indonesia) memproyeksikan industri ini tumbuh 5\% pada 2019. Apalagi peluang pasar masih terbuka dan kapasitas produksi pulp dan kertas meningkat karena ada perluasan. (Annisa Sulistyo Rini, 2019).

Indonesia merupakan salah satu penghasil pulp dan kertas terbaik di dunia. Agar peningkatan produksi pulp dan kertas meningkat dengan baik maka diperlukan bahan-bahan kimia penunjang yang berkualitas. Beberapa bahan kimia dalam produksi pulp dan kertas adalah Hidrogen peroksida $\left(\mathrm{H}_{2} \mathrm{O}_{2}\right)$, dan Klorin dioksida $\left(\mathrm{ClO}_{2}\right)$ yang digunakan sebagai bahan pemutih pulp dalam proses bleaching. Bleaching merupakan proses penghilangan sisa-sisa lignin yang masih tersisa dari proses pemasakan. Tujuan dari bleaching adalah meningkatkan derajat keputihan dan menghilangkan sisa lignin yang ada, maka dari itu bahan kimia pemutih memiliki peranan penting dalam proses bleaching pulp.

Seiring dengan meningkatnya produksi pulp dan kertas untuk proses bleaching mengakibatkan kebutuhan bahan pemutih juga mengalami kenaikan. Diperkirakan pada tahun 2007 di Amerika Serikat, kebutuhan bahan pemutih mencapai sekitar 12,5 miliar
Ib (Bayer et al, 1999). Namun pada saat ini bahan pemutih yang banyak digunakan dalam pembuatan pulp adalah senyawa yang mengandung chlor. Oksidasi senyawa yang mengandung chlor ini menghasilkan senyawa-senyawa yang sangat berbahaya seperti chloroform dan chloro nitromethane yang sangat berbahaya bagi kesehatan. Mengingat betapa berbahaya proses pemutihan dengan kandungan chlor maka perlu dilakukan penelitian untuk mencari alternatif. Pada penelitian kali ini, dilakukan penambahan $\mathrm{H}_{2} \mathrm{O}_{2}$ dan pada dosis berapa yang mencapai standar. Selain itu, dengan adanya penambahan hidrogen peroksida maka akan dapat diketahui apakah kualitas pulp yang dihasilkan memenuhi standar EOP stage. Penelitian ini dilakukan di PT. OKI Pulp and Paper Mills tepatnya dilaboratorium QAP pulp physical. Berdasarkan hal-hal di atas yang melatarbelakangi penulis untuk melakukan penelitian dengan judul "Optimasi Pengaruh Penambahan $\mathrm{H}_{2} \mathrm{O}_{2} \quad$ Terhadap Kualitas Pulp di EOP Stage". Tujuan dari penelitian ini adalah untuk mengetahui pengaruh penambahan hidrogen peroksida terhadap kualitas pulp (kappa number, viscosity, brightness), untuk mengetahui dosis optimum penambahan hidrogen peroksida terhadap pulp, dan untuk mengetahui dosis yang standar sesuai di EOP stage lalu menyimpulkan dosis yang terbaik. Dengan adanya penelitian, ini diharapkan dapat menjadi acuan yang dipakai oleh pabrik dan menjadi bahan evaluasi untuk hasil yang lebih baik.

Hidrogen peroksida atau $\mathrm{H}_{2} \mathrm{O}_{2}$ merupakan salah satu bahan kimia untuk proses pemutihan pulp. $\mathrm{H}_{2} \mathrm{O}_{2}$ menjadi bahan kimia yang lebih aman digunakan dibandingkan 
$\mathrm{ClO}_{2} \cdot \mathrm{H}_{2} \mathrm{O}_{2}$ ditambahkan pada tahap ekstraksi alkali atau EOP. Pada tahap ektraksi bukan hanya $\mathrm{H}_{2} \mathrm{O}_{2}$ yang ditambahkan tetapi ada oksigen dan $\mathrm{NaOH}$ yang membuat $\mathrm{H}_{2} \mathrm{O}_{2}$ bereaksi dalam suasana basa. Tujuan dari ekstraksi tersebut adalah melarutkan komponen-komponen penyebab warna yang kemungkinan besar larut dalam larutan alkali yang hangat berdasarkan dari bahan kimia yang digunakan terhadap sebagian pemutihan (Sirait, 2003). Di samping itu, hidrogen peroksida juga mempunyai beberapa kelebihan antara lain pulp yang diputihkan mempunyai ketahanan yang tinggi serta penurunan kekuatan serat sangat kecil. Pada kondisi asam, hidrogen peroksida sangat stabil, pada kondisi basa mudah terurai. Peruraian hidrogen peroksida juga dipercepat oleh naiknya suhu. Reaksi dekomposisi $\mathrm{H}_{2} \mathrm{O}_{2}$ yang terjadi sebagai berikut:

$$
\mathrm{H}_{2} \mathrm{O}_{2} \rightarrow 1 / 2 \mathrm{O}_{2}+\mathrm{H}_{2} \mathrm{O}
$$

Pemutihan dengan $\mathrm{H}_{2} \mathrm{O}_{2}$ ini memiliki beberapa keuntungan seperti waktu pengerjaan yang singkat karena saat proses pengerjaan dengan menaikkan suhu hingga $85^{\circ} \mathrm{C}$ secara konstan selama \pm 1 jam, maka serat akan lebih cepat diputihkan. Hasil pemutihan baik dan rata dengan proses pemanasan maka warna asli pada serat dapat terurai dan bahan menjadi lebih putih dan rata. Brightness pulp yang dihasilkan juga stabil, tidak mudah menjadi kuning. Kemungkinan kerusakan kecil karena daya oksidasi $\mathrm{H}_{2} \mathrm{O}_{2}$ lebih kecil.

\section{METODOLOGI PENELITIAN}

\subsection{Bahan dan Alat}

Adapun Bahan yang digunakan dalam penelitian ini antara lain bahan baku pulp yang berasal dari washpress 7 after dhot,
$\mathrm{H}_{2} \mathrm{O}_{2}$ berasal dari laboratorium demin water, $\mathrm{NaOH}$, kemudian bahan untuk pengujian pulp tersebut terdiri dari $\mathrm{KMnO}_{4}, \mathrm{H}_{2} \mathrm{SO}_{4}$, indikator starch (ss), KI, $\mathrm{Na}_{2} \mathrm{~S}_{2} \mathrm{O}_{3}$, larutan CED, dan kertas saring.

Alat yang digunakan dalam penelitian ini antara lain neraca digital, beaker glass, spuit (Suntikan), waterbath, gelas ukur, plastik, mesh ukuran 80, pipet volume, karet gelang, dehydrator, dan spidol. Sedangkan peralatan pengujian yang digunakan adalah viscometer oswald, buret, elrepho brightness tester, magnetic stirrer, pipet tetes, oven, dan tray aluminium serta $\mathrm{pH}$ meter.

\subsection{Metode}

Metode pada penelitian terdiri dari:

1. Persiapan bahan

a. Persiapan bahan baku pulp yang sudah melalui pengecekan awal (KaNO, viscosity, brightness dan konsistensi)

b. Persiapan alat waterbath dan beberapa plastik untuk dimasukan pulp tersebut.

c. Persiapan bahan kimia hidrogen peroksida dengan dosis $\mathrm{NaOH} 10,6 \mathrm{ml}$, konsistensi 10\%,waktu 60 menit, suhu 85 ${ }^{\circ} \mathrm{C}$, menggunakan variasi dosis $\mathrm{H}_{2} \mathrm{O}_{2}: 0,3$; 0,$4 ; 0,6 ; 0,7$ dan $0,9 \mathrm{ml}$.

2. Pelaksanaan Proses dengan tahap sebagai berikut:

- Pulp diambil 200 gr OD (oven $d r y$ ) kemudian dilarutkan dengan air sebanyak $2000 \mathrm{ml}$.

- Kemudian setelah dilarutkan maka didapat untuk konsistensi $10 \%$ masukan kedalam plastik.

- Gunakan alat pelindung diri sesuai standar seperti masker dan jas laboratorium.

- Lalu inject $\mathrm{NaOH}$ sebanyak 10,6 $\mathrm{ml}$. 
- Kemudian inject $\mathrm{H}_{2} \mathrm{O}_{2}$ dari variasi $0,3 \mathrm{ml}, 0,4 \mathrm{ml}, 0,6 \mathrm{ml}, 0,7$ $\mathrm{ml}$ dan $0,9 \mathrm{ml}$.

- Aduk pulp bersama bahan kimia tersebut sampai merata hingga warnanya juga merata.

- Tambahkan plastik lagi untuk melapisi plastik awal agar tidak terjadi kebocoran.

- Tutup dan ikat dengan rapat plastik dengan karet gelang sampai tidak ada udara dalam plastik.

- Setelah itu siapkan waterbath sebagai alat untuk bleaching.

- Isi air demin dalam waterbath hingga sesuai kebutuhan.

- Atur suhu dalam waterbath yaitu $85^{\circ} \mathrm{C}$ dan set waktu selama 1 jam.

- Setelah itu angkat pulp tersebut kemudian di press dan washing.

- Siapkan mesh ukuran 80 dan lakukan press dan washing pada pulp tersebut.

- Ambil filtrat awal untuk di cek kadar $\mathrm{pH}$, kemudian siapkan dehydrator untuk mengeringkan pulp lalu masukan pulp pada mesh ukuran 80 .

- Siapkan dehydrator dan masukan pulp kedalam dehydrator agar air yang masih tersisa dalam pulp berkurang

- Setelah itu ambil pulp dan siap untuk diuji.

\section{Hasil dan Pembahasan}

\subsection{Data Sampel Awal}

Tabel 1. Sampel Awal

\begin{tabular}{|l|c|}
\hline Data Sampel & Hasil \\
\hline Konsistensi & $26,19 \%$ \\
\hline Kappa Number & 3,2 \\
\hline
\end{tabular}

\begin{tabular}{|l|c|}
\hline Viscosity & $795 \mathrm{~cm}^{3} / \mathrm{g}$ \\
\hline Brightness & $65,18 \%$ \\
\hline pH Outlet Dhot & 3,3 \\
\hline COD & $7,0 \mathrm{~kg} / \mathrm{ADT}$ \\
\hline
\end{tabular}

\subsection{Pembahasan Hasil Bleaching $\mathrm{H}_{2} \mathrm{O}_{2}$}

\section{Pengaruh Dosis $\mathrm{H}_{2} \mathrm{O}_{2}$ Terhadap Kappa}

\section{Number}

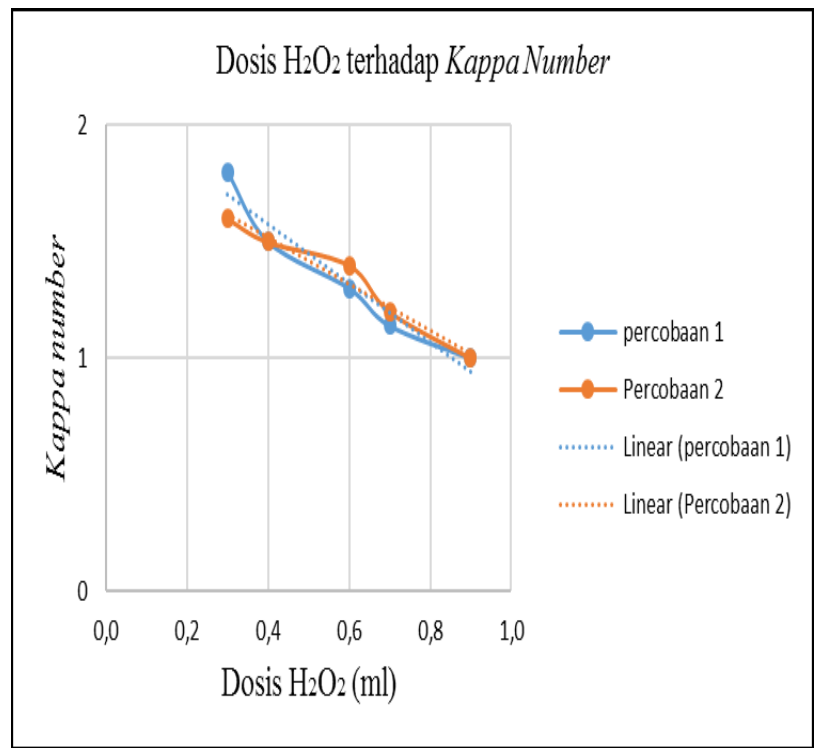

Grafik 1. Pengaruh Dosis $\mathrm{H}_{2} \mathrm{O}_{2}$ Terhadap Kappa Number

Berdasarkan 2 percobaan di atas dapat kita simpulkan bahwa kappa number yang standar pada tahap EOP stage adalah $<2$, namun berdasarkan hasil percobaan 1 dan 2 diketahui bahwa kappa number yang di dapat dari semua variasi berada dibawah 2, sehingga kappa number tersebut sudah sesuai dengan standar kappa number pada EOP stage. 


\section{Pengaruh Dosis $\mathrm{H}_{2} \mathrm{O}_{2}$ Terhadap}

Viscosity

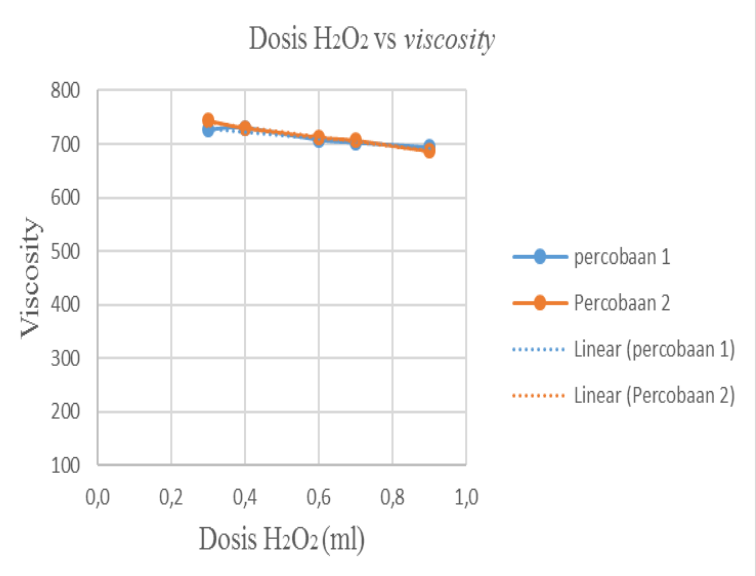

Grafik 2. Pengaruh Dosis $\mathrm{H}_{2} \mathrm{O}_{2}$ Terhadap Viscosity

Berdasarkan pada grafik di atas, dapat disimpulkan bahwa pengaruh penambahan dari dosis $\mathrm{H}_{2} \mathrm{O}_{2}$ terhadap pulp yang berbanding terbalik membuktikan yaitu semakin tinggi dosis diberikan maka viscosity dari pulp semakin menurun. Kelebihan dari bahan kimia penambahan $\mathrm{H}_{2} \mathrm{O}_{2}$ dibanding bahan pemutih lain seperti $\mathrm{ClO}_{2}$ adalah pulp yang diputihkan memiliki ketahanan yang tinggi serta penurunan kekuatan serat yang kecil (Fuadi, Ahmad, 2008). Berbeda dengan $\mathrm{ClO}_{2}$, pemutihan pulp diiringi dengan degradasi selulosa yang banyak, karena degradasi selulosa tersebut maka kekuatan ketahanan serat juga menurun sehingga akan berefek pada kualitas kertas yaitu kekuatan tariknya menurun (Fuadi, Ahmad, 2008).

\section{Pengaruh Dari Dosis $\mathrm{H}_{2} \mathrm{O}_{2}$ Terhadap Brightness}

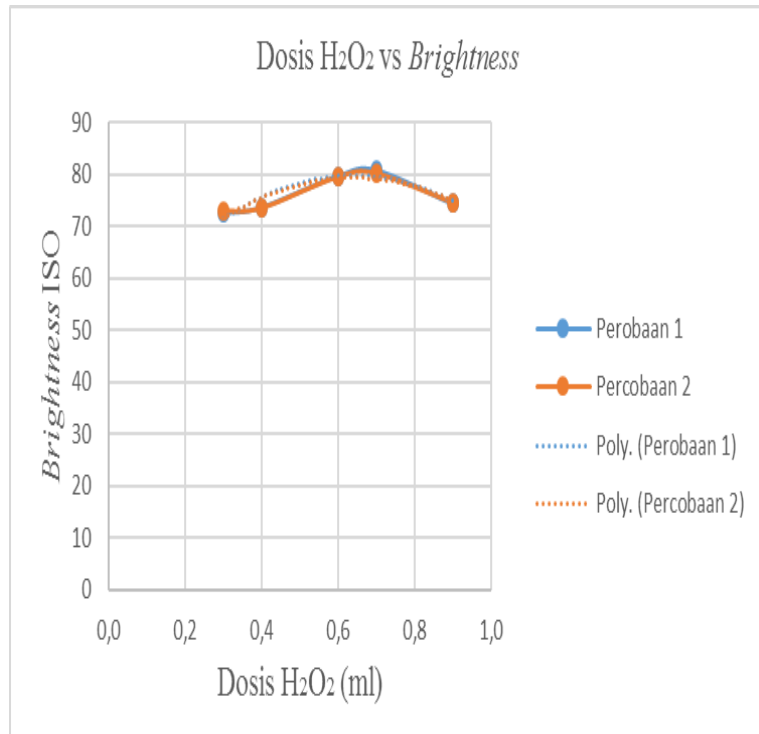

Grafik 3. Pengaruh Dosis $\mathrm{H}_{2} \mathrm{O}_{2}$ Terhadap Brightness

Brightness ISO merupakan parameter untuk melihat tingkat kecerahan pada pulp. Berdasarkan grafik di atas pengaruh penambahan $\mathrm{H}_{2} \mathrm{O}_{2}$ sangat identik dengan brightness, pada percobaan 1 dan percobaan 2 seharusnya secara teori semakin tinggi dosis $\mathrm{H}_{2} \mathrm{O}_{2}$ maka brightness yang dihasilkan akan lebih tinggi, namun hal ini tidak berlaku pada bahan pemutih $\mathrm{H}_{2} \mathrm{O}_{2}$. Pada dosis $0,3 \mathrm{ml}, 0,4 \mathrm{ml}$, 0,6 $\mathrm{ml}, 0,7 \mathrm{ml}$ dosis yang semakin tinggi mengakibatkan brightness semakin tinggi, tetapi pada dosis $0,9 \mathrm{ml}$ brightness yang dihasilkan menjadi turun. Hal ini disebabkan karena dekomposisi $\mathrm{H}_{2} \mathrm{O}_{2}$ yang dipercepat karena adanya metal ion di dalam pulp, sehingga sebagian besar $\mathrm{H}_{2} \mathrm{O}_{2}$ yang ditambahkan terdekomposisi menjadi air dan oksigen tanpa memberikan efek terhadap naiknya brightness (Fuadi, Ahmad, 2008). Hidrogen peroksida ketika ditambahkan akan bereaksi dengan metal ion kemudian sisanya bereaksi dengan lignin, tetapi pada dosis $0,9 \mathrm{ml}$ hidrogen peroksida sudah mencapai titik 
jenuhnya sehingga tidak bisa efektif dalam memutihkan pulp (Fuadi, Ahmad, 2008). Hasil yang lebih baik akan di tunjukan apabila melakukan penambahan chelating agent yang merupakan chemical untuk mengurangi metal ion logam berat (Fuadi, Ahmad, 2008). Brightness adalah hal yang terpenting dalam proses bleaching wajar apabila brightness rendah berarti lignin yang terkandung di dalam pulp masih banyak (Dence, Reeve, 1996).

\section{Dosis $\mathrm{H}_{2} \mathrm{O}_{2}$ pada End pH Target}

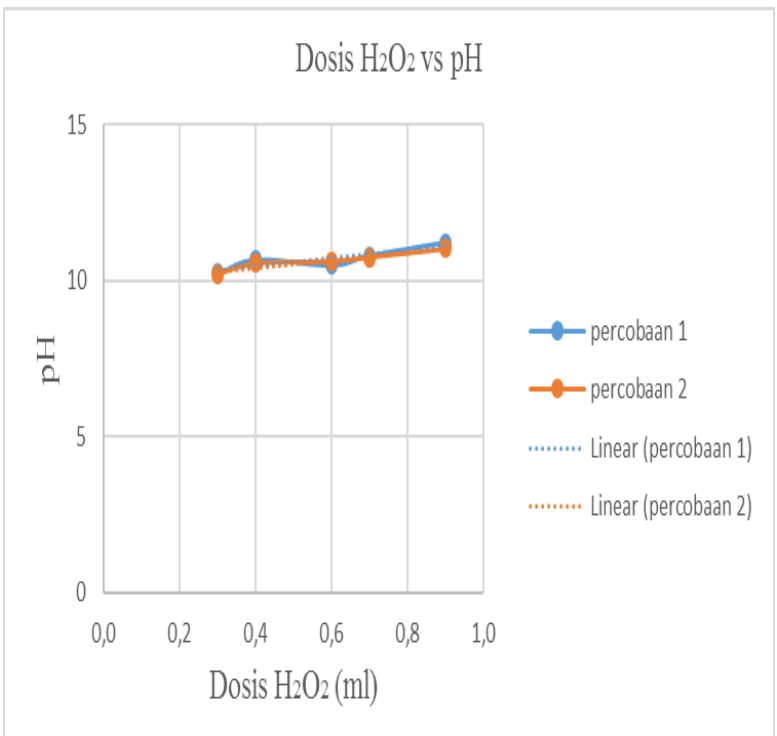

Grafik 4. Dosis $\mathrm{H}_{2} \mathrm{O}_{2}$ pada End pH Target

Berdasarkan grafik di atas menunjukan bahwa pada percobaan 1 dan percobaan 2 pengaruh penambahan dosis $\mathrm{H}_{2} \mathrm{O}_{2}$ dari masingmasing variasi tersebut seharusnya tidak meningkatkan nilai $\mathrm{pH}$. Nilai $\mathrm{pH}$ di dapat setelah menguji filtrat pada saat selesai proses bleaching dengan tujuan pulp yang di bleaching berada pada suasana basa. Nilai basa tersebut di dapat karena adanya penambahan $\mathrm{NaOH}$ yang menaikkan $\mathrm{pH}$ sedangkan hidrogen peroksida sendiri bersifat asam. Pada dosis $0,9 \mathrm{ml}$ tersebut sebenarnya memiliki pengaruh, namun karena adanya metal ion $\mathrm{Mn}, \mathrm{Fe}$, dan $\mathrm{Cu}$ yang dapat menurunkan keefektifan hidrogen peroksida untuk memutihkan pulp sehingga hidrogen peroksida mencapai titik jenuhnya (Fuadi, Ahmad, 2008). Sumber metal ions itu sendiri adalah dari pulp. Pengendalian dekomposisi hidrogen peroksida itu sangat penting, karena dekomposisi meningkat tajam dengan adanya ion-ion logam transisisi. Pengendalian dari metal ion ini dapat menggunakan bahan kimia chelating agent seperti EDTA, $\mathrm{MgSO}_{4}$, dan $\mathrm{H}_{2} \mathrm{SO}_{4}$ dengan begitu hasil dari pulp dapat lebih baik dan peningkatan nilai brightness akan signifikan (Fuadi, Ahmad, 2008).

\section{KESIMPULAN}

1. Pada percobaan 1 dan 2 kappa number paling tinggi berada pada dosis $0,3 \mathrm{ml}$ yaitu 1,8 dan 1,6, sedangkan kappa number paling rendah berada pada dosis $0,9 \mathrm{ml}$ yaitu 1 dengan begitu semakin banyak penambahan $\mathrm{H}_{2} \mathrm{O}_{2}$ maka kappa number akan turun. Pada percobaan 1 dan 2 viscosity paling rendah berada pada 0,9 $\mathrm{ml}$ yaitu $694 \mathrm{~cm}^{3} / \mathrm{g}$ dan $688 \mathrm{~cm}^{3} / \mathrm{g}$ sedangkan viscosity yang berada $>700$ adalah pada dosis $0,3 \mathrm{ml}, 0,4 \mathrm{ml}, 0,6 \mathrm{ml}$, $0,7 \mathrm{ml}$. Kemudian brightness yang optimal berada pada sampel $0,6 \mathrm{ml}$ dan 0,7 ml yaitu 79,62 \%, 79,45\%, 80,73\% dan $80,12 \%$ dengan perolehan diatas $78 \%$.

2. Berdasarkan hasil penelitian, dosis yang optimal berada pada $0,6 \mathrm{ml}$ dan $0,7 \mathrm{ml}$. Hal tersebut disebabkan karena kappa number yang diperoleh $<2$ lalu viscosity $>700$ $\mathrm{cm}^{3} / \mathrm{g}$ dan brightness $>78 \%$.

3. Standar kualitas EOP stage berada pada $78-80 \%$ brightness ISO dan filtrat $\mathrm{pH} 10,5-$ 10,8 sehingga dosis yang memenuhi standar tersebut adalah pada sampel $0,6 \mathrm{ml}$ dan $0,7 \mathrm{ml}$ 


\section{DAFTAR PUSTAKA}

1. Anonim. Bab II Tinjauan Pustaka (Online).(Pdf. Http://Eprints.Polsri.Ac.Id., Diakses 21 Juni 2021.

2. Dence, C. W. dan Reeve, D. W. 1996. Pulp Bleaching Principle and Practice, hal:349-415, Tappi Press, Atlanta.

3. Fuadi, Ahmad. 2008. Pemutihan Pulp Dengan Hidrogen Peroksida. Yogyakarta : Jurusan Teknik Kimia Fakultas Teknik UGM.

4. Sirait, S. 2003. Bleaching Module, Training and Development Centre, Porsea, PT. Toba Pulp Lestari. Tbk.

5. Sulistyo Rini, Annisa. 2019. Industri Pulp Dan Kertas Indonesia Masuk 10 Besar Dunia.https://ekonomi.bisnis.com/ read/20190127/257/882862/industripulpdan-kertas-indonesia-masuk-10-besardunia (diakses 29 Juni 2020). 